Original Research Paper

\title{
The Effect of Needle-Leaved Species in Increasing the Risk of Fire by Using Remote Sensing, Case Study: Forests of Golestan, Iran
}

\author{
${ }^{1}$ Akram Karimi, ${ }^{2}$ Sara Abdollahi, \\ ${ }^{3}$ Hamid Reza Kabiri Balajadeh, ${ }^{4}$ Kaveh Ostad-Ali-Askari and ${ }^{5}$ Vijay P. Singh \\ ${ }^{I}$ Department of Environmental Science, Evaluation Land use Planning, Karaj Environmental Faculty, Iran \\ ${ }^{2}$ Department of Environmental Science, Yazd University, Yazd, Iran \\ ${ }^{3}$ Graduate in Natural Resources Engineering, \\ Habitat and Biodiversity, Science and Research Branch, Islamic Azad University, Tehran, Iran \\ ${ }^{4}$ Department of Civil Engineering, Isfahan (Khorasgan) Branch, Islamic Azad University, Isfahan, Iran \\ ${ }^{5}$ Department of Biological and Agricultural Engineering and Zachry Department of Civil Engineering, \\ Texas A and M University, 321 Scoates Hall, 2117 TAMU, College Station, Texas 77843-2117, USA
}

Article history

Received: 23-02-2018

Revised: $17-03-2018$

Accepted: 30-03-2018

Corresponding Author: Kaveh Ostad-Ali-Askari Department of Civil Engineering, Isfahan (Khorasgan) Branch, Islamic Azad University, Isfahan, Iran Email: koa.askari@khuisf.ac.ir

\begin{abstract}
The present research was conducted to determine the sensitivity of needle-leaved species compared to broad-leaved in causing a natural fire in Golestan province. Vegetation and moisture stresses of plants were studied in both needle and mixed leaved forest the fire occurred in 20102014. In order to examine the normal condition of each indicator, the time series was produced from 2000 to 2015. The threshold of the applied indicators was determined using its long-term normal. The threshold value was determined as an average of 15 days before the fire, as well as on the day before the fire. The results showed that the amount of dry matter increased in the affected areas and the plants were exposed to moisture stress. Among the indicators used in this study, GVMI shows more sensitivity to fire rather than other indicators with a higher nominal frequency. In the broadleaf forest of (1.803) and in the forest forests (1.63), there is a decrease compared to the time series. Generally, these needleleaved species have a lower tolerance to moisture stress than the broadleaf.
\end{abstract}

Keywords: Broad Leaved, Fire, Needle Leaved, MODIS Satellite, Moisture Stress Index

\section{Introduction}

Fire is one of the most serious environmental phenomena that annually causes huge damages throughout the world in terms of economic, social, ecological and humanitarian hazards (Germ Jn et al., 2005). Fire is one of the main causes of natural ecosystems destruction, which annually causes significant damages to these areas. Today, fire is one of the most common destructive factors of natural ecosystems after drought, urban activities and human agriculture (Yin et al., 2004). The forest fire is one of the main concerns in many parts of the world not only from an environmental point of view but also from an economic, social and security perspective (Milir and Hays, 1995). Through the Middle East and North Africa, Iran is ranked as the fourth country in terms of forest fire (Adab et al., 2011). The highly sensitive species in the fire causes a natural fire. Hence, it is necessary to find out the level of resistance of forest types to the creation of fire for accurate forest management (Demir et al., 2009). Needle leaved are lighter than broad-leaved i.e. they have fewer wooden cubes in volume unit and therefore have less water content in wood warps that evaporates earlier by heating. Thus, the needle leaved vegetation is less resistant to fire than broad-leaved (Baranifard et al., 2015). Over the past years, fires that occurred in the Golestan forest areas are often found in pine coniferous parts due to the high combustion rate of dried needle leaves (gum and resin) Watershed Management Organization (FRWO). Accordingly, the moisture stresses of plants can be calculated in long-term periods using remote sensing data. The spectral properties of plants at different wavelengths are affected by the internal and external cellular structure of the leaved, as well as the 
concentration and composition of biochemical substances such as the amount of chlorophyll and nitrogen in the plant and its morphological factors (Demarez et al., 1999; Clark et al., 2005). Murta and Bozer (2009) have estimated the vegetation water situation, which is an important element in estimating forest fire risk assessment to predict the risk of fire. In this research, the probability of a fire is predicted to be $62 \%$. Also, Makia et al. (2004) have applied the vegetation water situation as well as measuring the relationship between leaved water content and the difference between the normal water indicator, near infrared and the confirmation of infrared shortwave spectral data to estimate the risk of fire risk. In another research in Alaska, the moisture content of trees and litter was measured and its relationship with fire was investigated (Jandt et al., 2005). Among the Iranian types of research, (Heydarhoo et al., 2014; Aghajani et al., 2014; Mohammadi, 2009; Jahdi et al., 2013; Darvishi et al., 2013; Nasiri, 2012). In all types of research, fire risk factors have generally been investigated. Moreover, the study area is classified as low-to-high risk areas. The role of different vegetation types has been less noticeable in creating fire. The purpose of this study was to determine the risk threshold in leaf plants compared with the fire for early warning of the fire possibility. The results of the research can be used in forest management.

\section{Materials and Methods}

\section{Study Area}

Golestan province is located in the southeast part of Caspian Sea. The total area of this province is 20,387 square kilometers that is about $1.3 \%$ of the country's total area. This province is located $36^{\circ} 30^{\prime}$ to $38^{\circ} 08^{\prime}$ northern latitude and $53^{\circ} 51^{\prime}$ and $56^{\circ} 22^{\prime}$ eastern longitude. The area of forests is 379,000 hectares in this province including 249,000 hectares of commercial, 70,000 hectares of protected and 60,000 hectares of ruined forests.

\section{Research Method}

In order to investigate the sensitivity of needle leaved species to broad leaved in creating natural fires, initially, the northern forests of Iran were evaluated and the Golestan province zone was selected with the highest number of fires compared to other zones "Fig. 4". 69 natural fires occurred in 2010-2014 were identified. The OLI Satellite Landsat (due to better spatial resolution of MODIS) was used to find out about the plant's location at the site of the fire and the separation of fires from Needle-Leaved, broad leaved and mixed leaved communities. For this purpose, the forest type map separated by needle leaved, broad leaved and mixed leaved, with Landsat satellite images, were created using a controlled classification with $85 \%$ precision.

Finally, the separation of fire points was carried out based on the forest type of the 69 surveyed fires, 42 cases were found in the Needle-Leaved forest type and another was found in the broad-leaved forest.

It should be noted that fires with unknown reason were omitted from the study due to the bias coverage. In the next step, used MODIS images for study the moisture stresses in the place of fire.

The selection of index type was based on the principle that the selection of needle leaved and broad leaved are in an identical visible spectrum, but the broad leaved have more reflections than needle leaved in the infrared range. Therefore, the indicators were selected to differentiate the differences between these forest types that have a band to distinguish needle leaved and broad leaved. Table 1 and 2 For this purpose, vegetation indicators such as NDVI, MSI and GVMI, which are most consistent with moisture stress and plant vegetation, were produced "Fig. 5(a-f)".

So, in this step, the Modis satellite images (MOD13Q1) were downloaded during 2000-2015. Then, the changes in the moisture content of the plants were recorded over the 15 years as the statistical data of the median, mean, maximum and minimum, to find out the difference in the behavior of the needle leaved species compared to the broad leaved. This was also monitored the month before the fire and the day before the fire by Vegetation indicators. Then, all previous steps were performed for the relative moisture index using the synoptic station data. In the final step, the best index was determined to set the severity of each type of forest by comparing the factors the day before the fire and the month before the fire as well as the time series. Then, the accuracy assessment was done to determine the precision of the sensitivity measured by the model.

Table 1: Data set characteristics MOD13Q1

\begin{tabular}{ll}
\hline Temporal coverage area & $\begin{array}{l}\text { February } 24,2000-\sim 10 \times 10 \\
\text { lat } / \text { long }\end{array}$ \\
\hline File size & $\sim 5-270 \mathrm{MB}$ \\
Data format & HDF-EOS \\
Dimensions & $4800 \times 4800$ rows/columns \\
Resolution & $250 \mathrm{~m}$ \\
\hline
\end{tabular}

Table 2: Science data sets for MODIS terra vegetation indicators and bands 16-day 13 global $250 \mathrm{~m}$ SIN Grid V005 (MOD13Q1) use this study

\begin{tabular}{ll}
\hline Science data sets (HDF Layers) (12) & BIT TYPE \\
\hline $250 \mathrm{~m} 16$ days NDVI & 16-bit signed integer \\
$250 \mathrm{~m} 16$ days red reflectance (Band 1) & 16-bit signed integer \\
$250 \mathrm{~m} 16$ days NIR reflectance (Band 2) & 16-bit signed integer \\
$250 \mathrm{~m} \mathrm{16}$ days MIR reflectance (Band 7) & 16-bit signed integer \\
\hline https://lpdaac.usgs.gov &
\end{tabular}




\section{Vegetation Indexes}

\section{Normalized Difference Vegetation Index}

NDVI is the most important vegetation index in remote sensing, which is widely used for analyzing land use changes including vegetation and other factors "2" Fig. 1. This index is suitable for areas with moderate and higher vegetation density because it is less susceptible to soil and effects of the atmosphere. However, it is not suitable for areas with less vegetation coverage. The equation of this index " 1 " is as follows.

"Figure 2" shows the NDVI index based on the greenness index. This index value varies from -1 to +1 and its function actually is based on high reflection of the healthy plant in NIR band and its low reflection in RED band of the electromagnetic spectrum (Pettorelli et al., 2005; Wang et al., 2003):

$$
N D V I=(N I R-R E D) /(N I R+R E D)
$$

\section{Moisture Stress Index}

This index is sensitive to increasing the leaf water content, which is used for analyzing vegetation coverage, predicting productivity and modeling, analyzing plant use conditions and studying ecosystem physiology Fig. 3 . The calculated value of this index is in the range of 0 to 3 and the usual value representing the vegetation coverage is in the range of 0.4 to 2 . Hunt and Rock (1989):

$$
M S I=M I R / N I R
$$

\section{Global Vegetation Moisture Index}

It is used to measure the amount of vegetation water. This index uses NIR and MIR MODIS bands Table 3. The higher the moisture content of the combustion the fire starts hardly. Therefore, increasing GVMI causes low fire. All three indicators were monitored for the pre-incident fire as a 15 -year series and an average of 30 days before the fire and the day before the fire occurred. The index (3) is calculated as follows, Ceccato et al. (2002):

$G V M I=\frac{(P 2+0.1)-(p 6+0.02)}{(P 2+0.1)+(P 6+0.02)}$

The presented maps cited a sample of fires that occurred on January 12, 2014, in the needle leaved forest type. The GVMI index shows the incidence of fire in a series time series and one month before the fire and the day before the fire occurred. Observations indicate that the fire location is potentially suitable for moisture (0.95), but there was some degree of moisture stress (0.02) in the month before the fire and the moisture stress was high and decreased to $(-0.97)$ the day before the occurrence of fire. Similarly, other indicators were calculated for each fire incident and the results of this section are summarized in "Table 4 and 5".

Table 3: Indicators of remote sensing used in research

\begin{tabular}{lll}
\hline Index & Formula & Source \\
\hline MSI & MIR/NIR & Hunt and Rock (1989) \\
NDVI & (NIR-Red)/(NIR+RED) & Rouse et al. $(1974)$ \\
GVMI & (NRI+0.1)-(MIR+0.2)/ & Ceccato et al. $(2002)$ \\
& $(\mathrm{NRI}+0.1)+(\mathrm{MIR}+0.2)$ & \\
\hline
\end{tabular}

Table 4: The studied the threshold relative to time series $(2000,2015)$

\begin{tabular}{|c|c|c|c|c|c|c|c|c|}
\hline & \multicolumn{2}{|c|}{$\begin{array}{l}\text { The threshold is based } \\
\text { on the mean value }\end{array}$} & \multicolumn{2}{|c|}{$\begin{array}{l}\text { The threshold is based } \\
\text { on the minimum value }\end{array}$} & \multicolumn{2}{|c|}{$\begin{array}{l}\text { The threshold is based } \\
\text { on the maximum value }\end{array}$} & \multicolumn{2}{|c|}{$\begin{array}{l}\text { The threshold is based } \\
\text { on the median value }\end{array}$} \\
\hline & Needle-leaved & $\begin{array}{l}\text { Broad leaf } \\
\text { forest }\end{array}$ & Needle-le & $\begin{array}{l}\text { Broad leaf } \\
\text { forest }\end{array}$ & Needle-leaved & $\begin{array}{l}\text { Broad leaf } \\
\text { forest }\end{array}$ & Needle-1 & $\begin{array}{l}\text { Broad leaf } \\
\text { forest }\end{array}$ \\
\hline GVMI $(-1,1)$ & 1.542 & 1.631 & 1.0600 & 1.23 & 0 & 1.8030 & 0. & 0.521 \\
\hline MSI $(0,+3)$ & 1.703 & 1.400 & 1.6600 & 1.42 & 1.8500 & 1.4610 & 0.890 & 0.750 \\
\hline NDVI $(-1,1)$ & 0.110 & 0.120 & 0.12 & 0.10 & & & 0.0 & 0.601 \\
\hline RH \% & 13.300 & 17.170 & 17.3600 & 19.22 & 19.6700 & 38.1800 & 15.110 & 18.780 \\
\hline
\end{tabular}

The threshold relative to time series $(2000,2015)$

Table 5: The threshold relative to mean a month before the fire

\begin{tabular}{|c|c|c|c|c|c|c|c|}
\hline \multicolumn{2}{|c|}{$\begin{array}{l}\text { The threshold is based } \\
\text { on the mean value }\end{array}$} & \multicolumn{2}{|c|}{$\begin{array}{l}\text { The threshold is based } \\
\text { on the minimum value }\end{array}$} & \multicolumn{2}{|c|}{$\begin{array}{l}\text { The threshold is based } \\
\text { on the maximum value }\end{array}$} & \multicolumn{2}{|c|}{$\begin{array}{l}\text { The threshold is based } \\
\text { on the median value }\end{array}$} \\
\hline Needle-leaved & $\begin{array}{l}\text { Broad leaf } \\
\text { forest }\end{array}$ & Needle-leaved & $\begin{array}{l}\text { Broad leaf } \\
\text { forest }\end{array}$ & Needle-leaved & $\begin{array}{l}\text { Broad leaf } \\
\text { forest }\end{array}$ & Needle-leaved & $\begin{array}{l}\text { Broad leaf } \\
\text { forest }\end{array}$ \\
\hline 1.509 & 1.5420 & 1.060 & 1.30 & 1.602 & 1.681 & 0.63 & 1.523 \\
\hline 1.30 & 1.8000 & 0.930 & 1.42 & 2.300 & 2.840 & 1.24 & 1.423 \\
\hline 0.11 & 0.1003 & 0.002 & 0.01 & 0.083 & 0.198 & 0.08 & 0.200 \\
\hline 28.22 & 31.4900 & 21.500 & 35.00 & 16.830 & 29.000 & 20.22 & 30.670 \\
\hline
\end{tabular}

The threshold relative to mean a month before the fire 


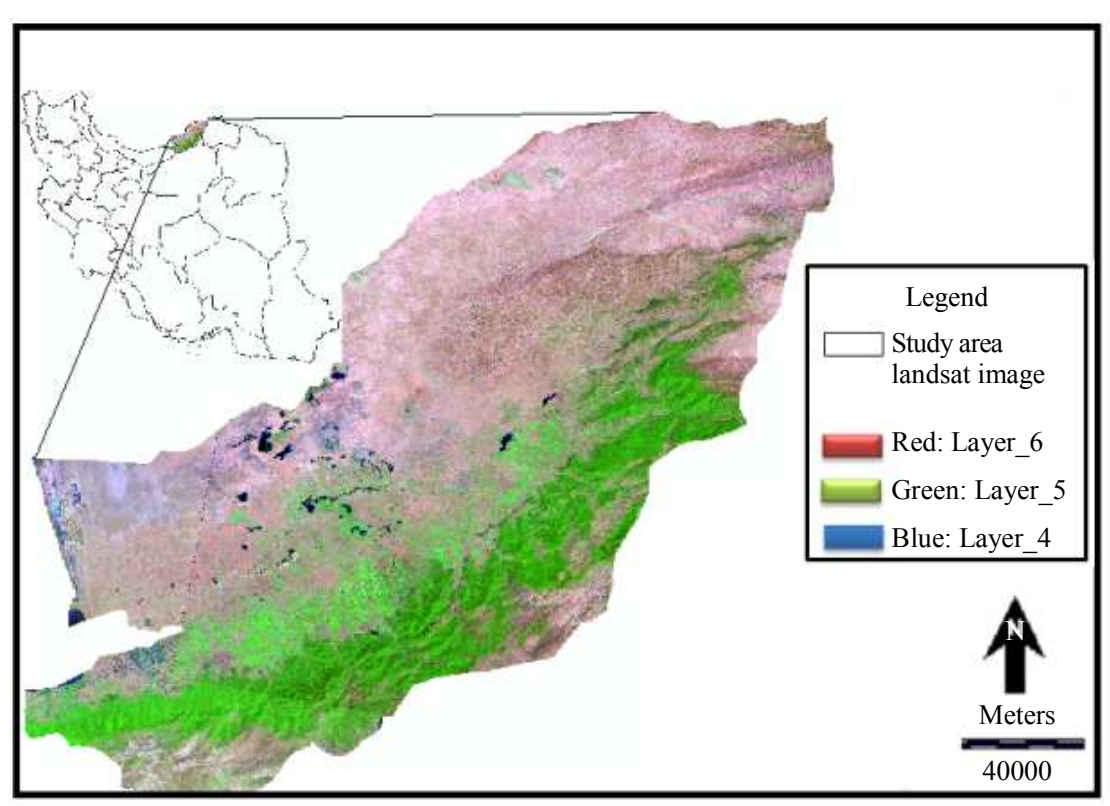

Fig. 1: The geographical location of the study area within Iran, Golestan, Iran
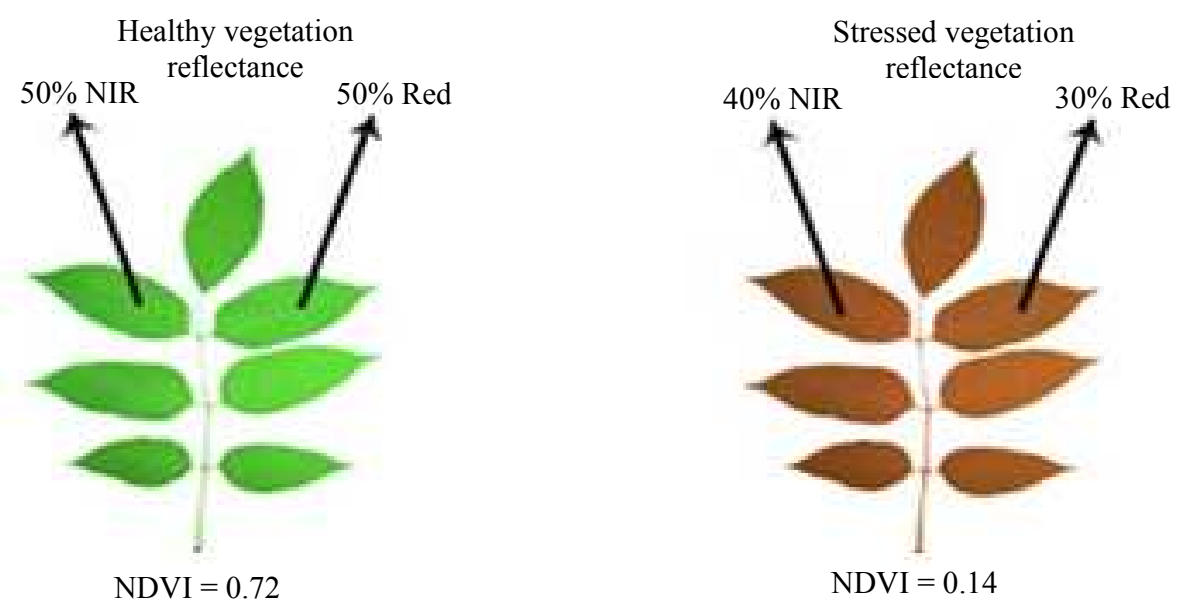

Fig. 2: NDVI index based on greenness index

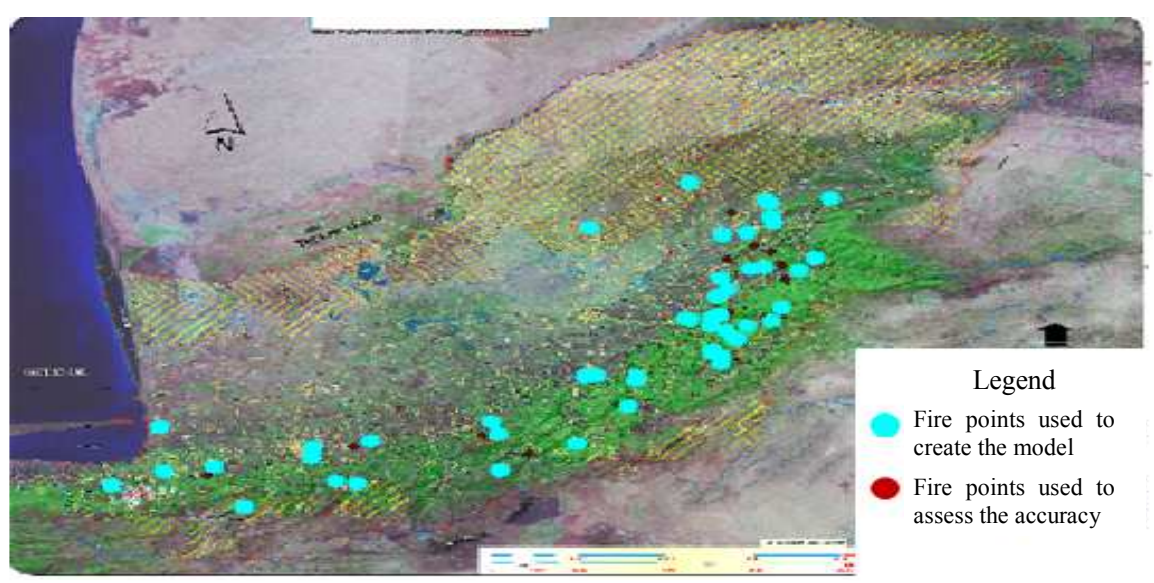

Fig. 3: The location of fire points used in research 


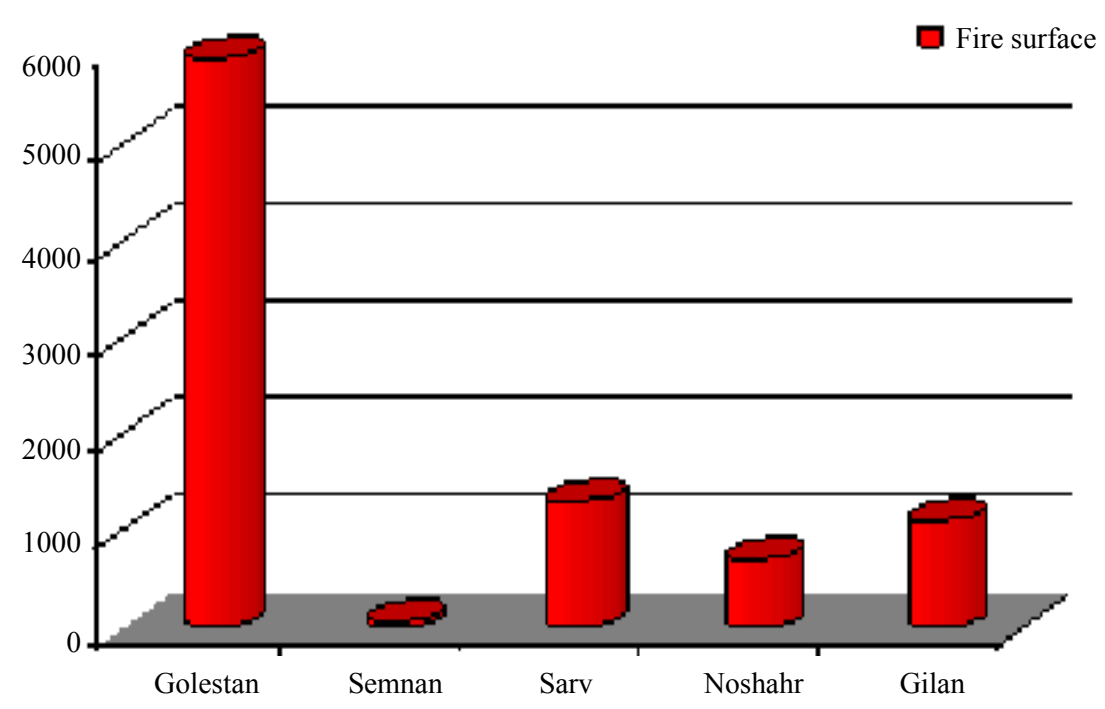

Fig. 4: Fire in the Northern provinces 2010-2014

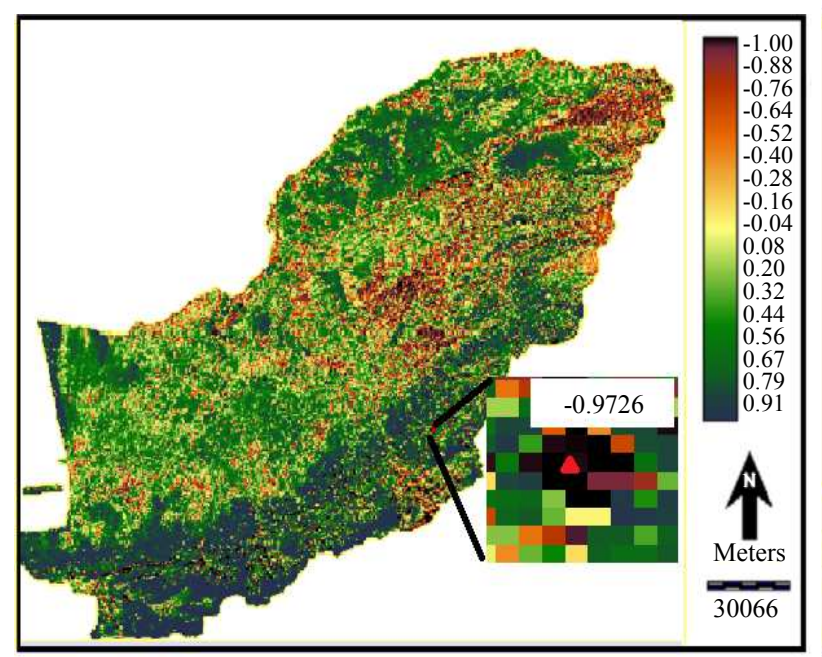

(a)

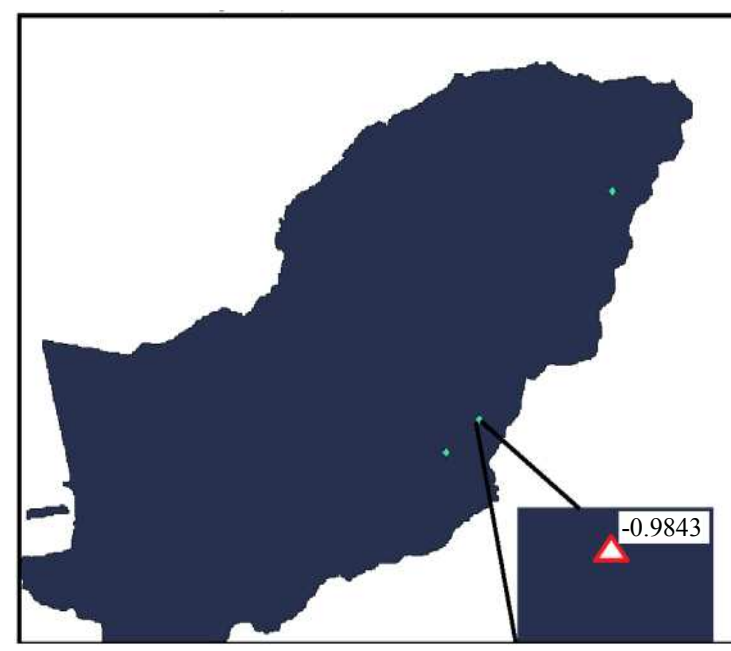

(c)

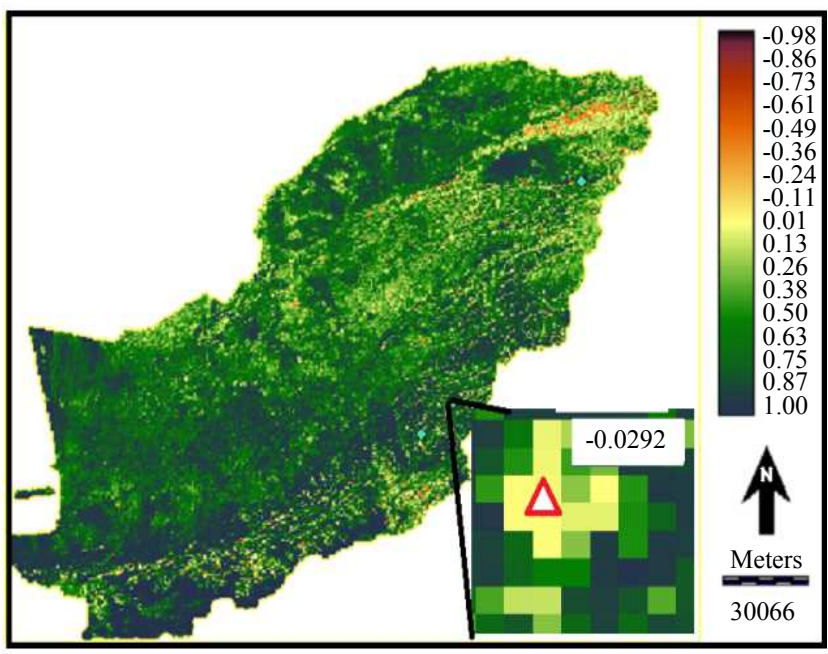

(b)

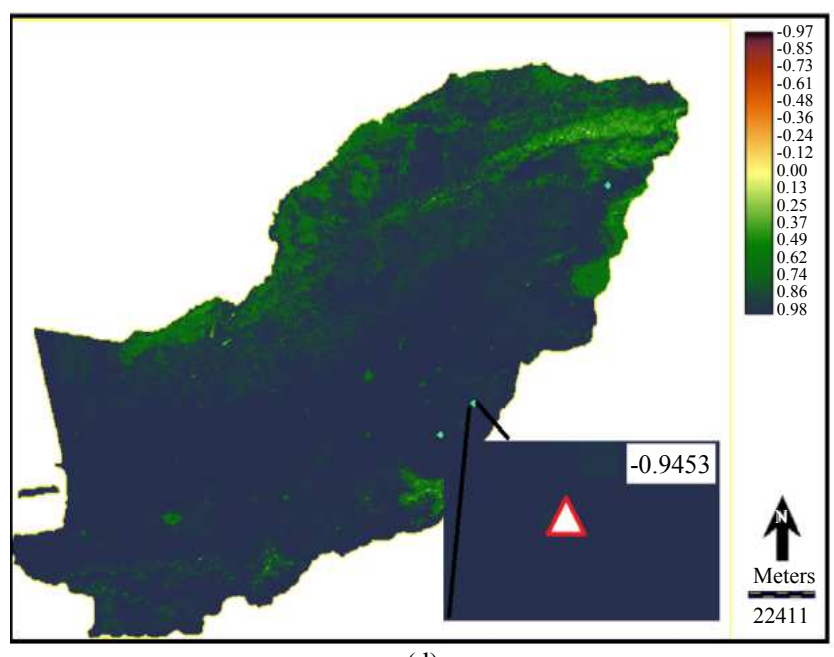

(d) 


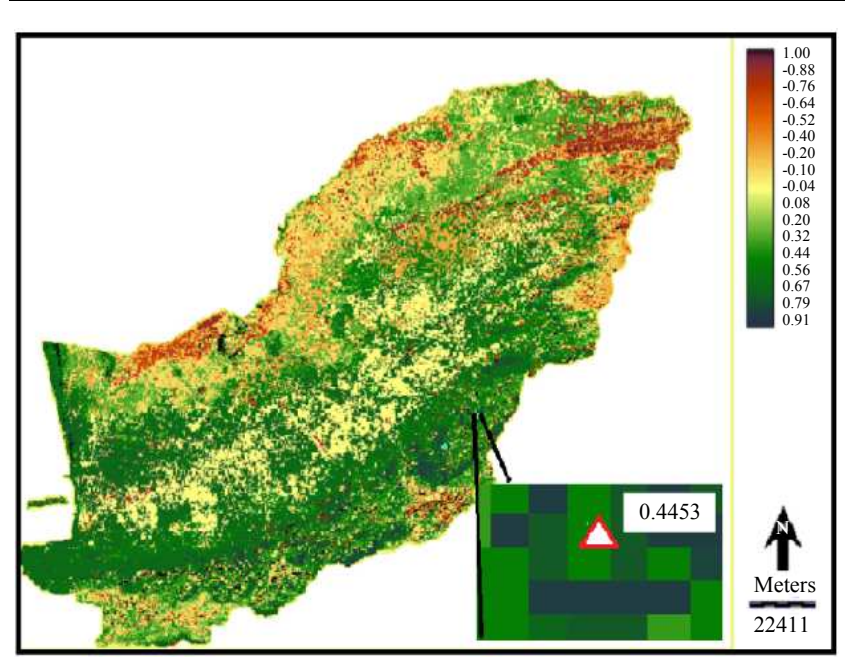

(e)

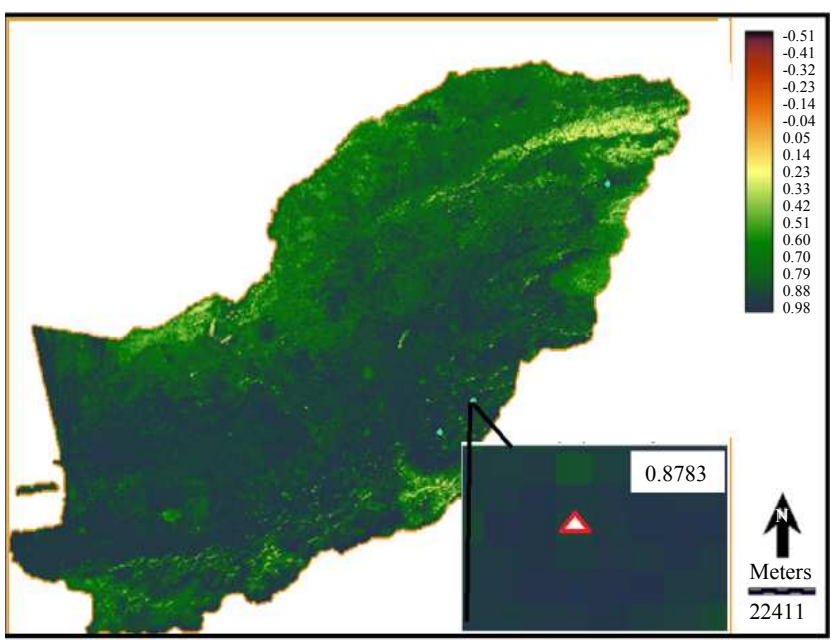

(f)

Fig. 5: (a) GVMI Index on January 12, 2015 at fire location (b) GVMI Index in the month before the fire (c) Maximum Time Series GVMI Index on January, 2000-2015 (d) Median Time Series Map on January, 2000-2015 (e) Minimum Time Series GVMI Index on January, 20002015 (f) Mean Time Series Map on January, 2000-2015

Table 6: Evaluation accuracy

\begin{tabular}{|c|c|c|c|c|c|c|c|c|}
\hline & \multicolumn{2}{|c|}{ Threshold of GVMI index } & \multicolumn{2}{|c|}{ Threshold of MSI index } & \multicolumn{2}{|c|}{ Threshold of NDVI index } & \multicolumn{2}{|c|}{ Threshold of RH } \\
\hline & $\begin{array}{l}\text { Needle-leaved } \\
\text { frost }\end{array}$ & $\begin{array}{l}\text { Broadleaf } \\
\text { frost }\end{array}$ & $\begin{array}{l}\text { Needle-leaved } \\
\text { frost }\end{array}$ & $\begin{array}{l}\text { Broadleaf } \\
\text { frost }\end{array}$ & $\begin{array}{l}\text { Needle-leaved } \\
\text { frost }\end{array}$ & $\begin{array}{l}\text { Broadleaf } \\
\text { frost }\end{array}$ & $\begin{array}{l}\text { Needle-leaved } \\
\text { frost }\end{array}$ & $\begin{array}{l}\text { Broadleaf } \\
\text { frost }\end{array}$ \\
\hline$\overline{\text { Accuracy\%} \%}$ & 94.44 & 95.33 & 66.67 & 52.94 & 41.18 & 29.41 & 94.44 & 91.07 \\
\hline KAPPA & 0.89944 & 0.904 & 0.4483 & 0.4625 & 0.3411 & 0.2416 & 0.8994 & 0.8209 \\
\hline
\end{tabular}

\section{Research Findings}

\section{Obtaining the Threshold}

The sensitivity of each index related to fire occurrence was measured by calculating the arithmetic mean of the factors studied in each event with its long duration. The fire thresholds were measured individually in both existing forest types.

Choosing the best index on this basis took place.

The index, that the greatest difference as compared to the time series (indicating normal conditions), is more accurate to show the ability to demonstrate the difference between the needle leaved from broad leaved in fire occurrence in order to select the best index, thus, in each index, the highest difference was chosen for the best threshold.

As indicated in the table above, the needle leaved species has a risk start on its the day before the fire with the $1.68 \%$ point in GVMI index compared to time series normal and $1.509 \%$ point has a risk start on its the day before the fire compared to the mean of a month before the fire while the broad leaved species need a moisture stress in the day before the fire of 1.803 or higher than their time series normal for risk starting and 1.542\% point has a risk start on its the day before the fire compared to the mean of a month before the fire. Therefore, the needle leaved species in lower moisture stress are also burned.

The Relative humidity of the air: The risk starting occurs with a decrease of the maximum moisture content relative to the long-term as much as $28.18 \%$ in broadleaf forests and $19.67 \%$ in needle leaved forests. This indicates the higher sensitivity of needle leaved species to environmental changes. In other words, needle leaved has a lower tolerance threshold than broad leaved against the occurrence of fire. Therefore, considering that the GVMI index has the highest difference over its time series period, it was selected as the best index to show the threshold.

About (1.68) in the needle leaved type and 1.8 reduction in the broadleaf forest type. In addition, the threshold for the relative humidity of the air also indicates that the most needle species of the leaf are sensitive to environmental stresses.

Then, the accuracy of the thresholds was evaluated on $30 \%$ of the fire points that are presented below.

According to the Table 6, it can be expressed: GVMI Index with an accuracy of $94.44 \%$ Needle-Leaved forest types and $95.33 \%$ broadleaf forest is able to index threshold with better accuracy to warn the risk of fire Rah offers. 


\section{Conclusion}

Natural fires are the result of interacting several factors, including increasing the temperature, reducing the moisture and the presence of dry matter. Therefore, the study of the moisture and heat stresses of plants can be effective in predicting the behavior of plants in creating natural fires. It is necessary to initially determine the moisture and heat of the plants in nonstress conditions. To this end, the 15 -year time series data were used. Then, the moisture was investigated in the days before the fire to monitor the moisture and heat stress during the fire. The sensitivity of each index relative to the occurrence of the fire was measured by calculating the arithmetic mean and the factors under investigation in each event with its time series. Regarding the fact that the index, which has the highest difference in the day before the accident with time series normal, can show the moisture stresses more accurately, the best index was chosen among the measured indicators. Then, the difference in the threshold of moisture stress in the needle leaved was measured in terms of broad leaved in the fire. Among the applied indicators, the GVMI indicators better showed the difference between the two forest types.

In this index, the threshold of risk in the broadleaf forest is 1.803 and in the needles 1.63 , the difference is compared to the time series. In general, these needle species of the leaf are less tolerant to stress than the broadleaf and sooner, under the influence of moisture stresses, they develop fire. The accuracy of the model in calculating the threshold of risk in the forest type of leaf needle and in the broadleaf forest type are 93.33 and 94.44 , respectively.

Generally, it can be said that broad leaved are more resistant in creating a fire than needle leaved. Needle leaved have fewer threshold due to having resins. Therefore, the needle leaved species should be imported and planted with more precision, control and monitoring compared to broadleaved forests due to their sensitivity. In addition, the resist broad leaved species should be used as a firefighter in the margin of needle leaved forests.

\section{Acknowledgement}

Finally, I know all honorable writers and professors who have great assistance in writing this article my thanks and appreciation.

\section{Funding Information}

All costs for the preparation, writing and publication of the article are provided by the authors of the paper.

\section{Author's Contributions}

In writing this article, the authors had an equal share of participation and participated in all stages, including writing, editing, arbitration and all stages of scientific work.

\section{Ethics}

In this article, all ethical principles related to scientificresearch articles such as validity and authenticity, originality, data collection in a standard manner, integrity and accuracy of research and etc. are observed.

\section{References}

Adab, H., D. Kanniah and K. Solaimani, 2011. GISbased probability assessment of fire risk in grassland and forested landscapes of golestan province, Iran. Proceedings of the International Conference on Environmental and Computer Science (ECS' 11).

Aghajani, H., A. Fallah and S.F. Emadian, 2014. Modelling and analyzing the surface fire behaviour in Hyrcanian forest of Iran. J. Forest Sci., 60: 353-362.

Baranifard, B., H. Ali and M.R. Khosravi, 2015. Investigation of wood fire resistance in needle leaved species compared to broad leaved in Golestan Province forests. Proceedings of the 2nd National Congress of Biology and Natural Sciences of Iran, (NSI' 15), Tehran, Center for Sustainable Development for Accessibility Tools and Mehr Arvand Education Institute.

Ceccato, P., N. Gobron, S. Flasse, B. Pinty and S. Tarantola, 2002. Designing a spectral index to estimate vegetation water content from remote sensing data. Part 1 Theoretical approach. Remote Sens. Environ., 82: 188-197. DOI: 10.1016/S0034-4257(02)00037-8

Clark, M.L., D.A. Roberts and D.B, Clark, 2005. Hyperspecteral disceimination of tropical of tropical rain forest tree species at leaf to crown scales. Remote Sens. Environ., 96: 375-398.

DOI: 10.1016/j.rse.2005.03.009

Darvishi, L., M. Ghods-Khah and V. Gholami, 2013. Presentation of the regional model for the zoning of fire hazard in the forests of Dorood (Case study of Babahor area). J. Res. Protect. Iranian Forests Rangelands, 11: 10-20.

DOI: 10.22092/ijfrpr.2013.106396

Demarez, V., J.P. Gastellu-Etchegorry, E. Mougin, G. Marty and C. Proisy et al., 1999. Seasonal variation of leaf chlorophyll content of a temperate forest Inversion of the PROSPECT model. Int. J. Remote Sens., 20: 879-894.

Demir, M., A. Küçükosmanolu, M. Hasdemir and H.H. Acar, 2009. Assessment of forest roads and firebreaks in Turkey. African J. Biotechnol., 8: 4553-4561.

Germun, B., C. Ana, M. Tomàs and L. Emilio, 2005. Wildland fire risk maps using S F M, computer architecture and operating systems department. Universitat Autnoma de Barcelona Bellaterra (Barcelona), 5: 244-249. 
Heydarhoo, B., H. Banej, A. Shafiei and M. Erfanian, 2014. Evaluation of fuzzy linear combination method in forest fire risk mapping (Case Study: Sardasht Forest, West Azarbaijan). J. Sci. Technol. Wood Forest.

Hunt, E.R. and B.N. Rock, 1989. Detection of changes in leaf water content using near- and middle-infrared reflectances. Remote Sens. Environ., 30: 43-54. DOI: 10.1016/0034-4257(89)90046-1

Jahdi, R., A. Darvishsefat and V. Etemad, 2013. Predicting forest fire spread using fire behavior model (Case study: Malekroud Forest-Siahkal). Iranian J. Forest Poplar Res., 5: 419-430

Jandt, R., J. Allen and E. Horschel, 2005. Forest floor moisture content a fire danger indicators in Alaska. Alaska Technical Report.

Makia, M., M. Ishiahra and M. Tamura, 2004. Estimation of leaf water status to monitor the risk of forest fires by using remotely sensed data. Remote Sens. Environ., 90: 441-450. DOI: 10.1016/j.rse.2004.02.002

Milir, D.E. and C.R. Hays, 1995. Missouri drought response plan. Water Resources Report.

Mohammadi, F., 2009. Preparation of forest fire hazard map using satellite imagery and GIS in a part of Paveh forest, Kurdistan Natural Resources Faculty, Kurdistan, Iran. NASA/GSFC, Type III, final report, Greenbelt, MD.
Murta, A. and R. Bozer, 2012. Estimation of the burned area in forest fires using computational intelligence techniques. Proc. Comput. Sci., 12: 282-285. DOI: 10.1016/j.procs.2012.09.070

Nasiri, M., 2012. Investigating the wood fire resistance of various species of Northern Forests (Case Study: Hardwood Roads). J. Forest Poplar Researches Iran, 20: 505-513. DOI: 10.22092/ijfpr.2012.107456

Pettorelli, N., J. OlvaVik, A. Mysterud, J.M. Gaillard and C.J. Tucker et al., 2005. Using the satellitederived NDVI to assess ecological responses to environmental change. J. Trends Ecol. Evolut., 20: 503-510. DOI: 10.1016/j.tree.2005.05.011

Rouse, J.W., R.H. Haas, D.W. Deering and J.A. Schell, 1974. Monitoring the vernal advancement and retrogradation (green wave effect) of natural vegetation, NASA technical reports.

Wang, Q., M. Watanabe, S. Hayashi and S. Murakami, 2003. Using NOAA AVHRR data to assess flood damage in Chaina. Environ. Monit Assess., 82: 119-148.

Yin, H., K. Fanhua and L. Xiu-Zhen, 2004. RS and GISbased forest fire risk zone mapping in da hinggan mountains. Chinese Geographical Sci., 14: 251-257. 